\title{
PERANCANGAN KNOWLEDGE MANAGEMENT SYSTEM PADA KOMITE TEKNIS
}

\section{Knowledge Management System Design on Technical Committee}

\author{
Yan Andriariza Ambhita Sukma ${ }^{1}$, Nur Indrawati ${ }^{2}$, Reza Zulfikar Ruslam ${ }^{3}$ \\ ${ }^{1}$ Kementerian Komunikasi dan Informatika, Jalan Medan Merdeka Barat No. 9 Jakarta Pusat \\ ${ }^{2}$ Kementerian Komunikasi dan Informatika, Jalan Medan Merdeka Barat No. 17 Jakarta Pusat \\ ${ }^{3}$ PT Agung Sedayu Group, AGS Headquarter, Jalan Pantai Indah Kapuk Boulevard, Jakarta Utara \\ e-mail: yana001@kominfo.go.id
}

\begin{abstract}
Abstrak
Standar Nasional Indonesia (SNI) memiliki peranan penting antara lain untuk perlindungan konsumen. Perumusan dan kaji ulang Standar Nasional Indonesia dilaksanakan oleh Komite Teknis dengan melibatkan pakar, pemerintah, pelaku usaha, dan konsumen. Belum terintegrasinya penyimpanan dokumen dan belum adanya sistem manajemen pengetahuan yang baik menyebabkan beberapa proses dalam perumusan dan kaji ulang SNI berjalan kurang lancar. Penelitian ini membahas bagaimana merancang Knowledge Management System (KMS) pada Komite Teknis guna mendukung pelaksanaan tugas dan tanggung jawab Komite Teknis. Dengan adanya KMS, dapat mendukung proses sharing knowledge dan pengambilan keputusan, sehingga pada akhirnya dapat meningkatkan kinerja Komite Teknis.
\end{abstract}

Kata kunci: knowledge management system, komite teknis, Standar Nasional Indonesia (SNI).

\begin{abstract}
Standar Nasional Indonesia (SNI) has important role, among others, for consumer protection. The formulation and review of SNI is carried out by Technical Committee involving expert, government, business actor, and consumer. Document storage is not integrated yet and the absences of good knowledge-management-system cause several processes in formulation and review to run less smoothless. This research discusses how to design Knowledge Management System (KMS) to support the implementation of task and responsibility of Technical Committee. KMS can support sharing knowledge and decision making process, so finally can improve Technical Committee performance.
\end{abstract}

Keywords: knowledge management system, technical committee, Standar Nasional Indonesia (SNI).

\section{PENDAHULUAN}

Komite Teknis merupakan Komite yang memiliki tugas dan tanggung jawab di bidang standardisasi. Tugas dan tanggung jawab Komite Teknis diatur dalam Peraturan Badan Standardisasi Nasional Nomor 4 Tahun 2018 tentang Pedoman Pengelolaan Komite Teknis. Tugas dan tanggung jawab Komite Teknis, yaitu: menyusun dan mengusulkan Program Nasional Perumusan Standar (PNPS), menetapkan konseptor dan editor RSNI, melaksanakan PNPS yang telah ditetapkan oleh Badan Standardisasi Nasional (BSN), melaksanakan pemeliharaan SNI sesuai ketentuan yang berlaku, menyusun dan merumuskan tanggapan Indonesia terhadap draft standar internasional dan dokumen lain yang terkait pengembangan standar internasional, melaksanakan tugas lain dalam rangka pengembangan standar nasional dan internasional sesuai kepentingan nasional, melaksanakan evaluasi program kerja dan partisipasi anggota Komite Teknis, dan menyusun laporan akhir tahun kinerja Komite Teknis. Komite Teknis beranggotakan paling banyak 15 (lima belas) orang yang merupakan perwakilan dari pemerintah, pakar, konsumen, dan pelaku usaha.

Pada proses perumusan dan pemeliharaan Standar Nasional Indonesia (SNI), Komite Teknis dapat dibantu oleh Kelompok Kerja-Kelompok Kerja dan konseptor nonanggota Komite Teknis. Dalam melaksanakan tugas dan tanggung jawab terkait perumusan SNI khususnya dalam sirkulasi dokumen rapat, hingga saat ini terdapat Sekretariat yang memanfaatkan media surat elektronik untuk proses sirkulasi dokumen. Proses sirkulasi dokumen rapat mengalami kendala saat ukuran file cukup besar sehingga menyebabkan file atau 
surat elektronik gagal dikirim. Selain itu, belum adanya media elektronik yang terintegrasi yang dapat digunakan bersama secara aman dan handal untuk menyimpan dokumen hasil rapat dan hasil kerja Komite Teknis dan Kelompok Kerja (Working Group) dari tahun ke tahun menyebabkan sulitnya sharing knowledge terutama saat terjadi pergantian personel.

Berdasarkan latar belakang yang disebutkan, maka diperoleh rumusan permasalahan yaitu bagaimana merancang Knowledge Management System (KMS) pada pelaksanaan tugas dan tanggung jawab Komite Teknis?

Tujuan dari penelitian ini adalah merancang Knowledge Management System (KMS) pada Komite Teknis untuk mendukung kegiatan dan meningkatkan kualitas kinerja Komite Teknis. Dengan adanya KMS, diharapkan dapat memberikan manfaat, antara lain dapat mempermudah dalam sharing knowledge dan pengambilan keputusan untuk meningkatkan kualitas kinerja Komite, serta Komite Teknis memiliki Knowledge Management System (KMS) yang mampu memberikan knowledge terkait tugas dan tanggung jawab Komite.

Penelitian ini dibatasi pada Komite Teknis dalam menjalankan tugas dan tanggung jawabnya sebagaimana tercantum dalam Peraturan Badan Standardisasi Nasional Nomor 4 Tahun 2018 tentang Pedoman Pengelolaan Komite Teknis. Pengembangan aplikasi pada penelitian ini menggunakan model Waterfall dan Unified Modeling Language (UML).

\section{TINJAUAN PUSTAKA}

\section{Knowledge Management System}

Knowledge Management (KM) menurut Tiwana (2002) didefinisikan secara luas meliputi aktivitas menciptakan, mengkomunikasikan, dan menerapkan pengetahuan yang diperlukan dan berguna bagi pencapaian tujuan bisnis. Sedangkan Knowledge Management System didefinisikan (Dalkir, 2005) sebagai penyimpanan virtual terhadap informasi yang relevan untuk tugas-tugas harian pada organisasi oleh knowledge worker. (Debowski, 2006) mendefinisikan knowledge worker sebagai pekerja yang menghabiskan sebagian besar waktunya untuk menciptakan, mengaplikasikan, dan menyampaikan knowledge.

Klasifikasi Knowledge Management System didasarkan pada observasi implementasi Knowledge Management System, yang terdiri dari Knowledge Discovery System, Knowledge
Capture System, Knowledge Sharing System, dan Knowledge Application System. ( Becerra, et al, 2010).

\section{Fase Penciptaan Knowledge Organisasi}

Kemampuan untuk mendistribusikan dan menduplikasi knowledge merupakan kunci dari nilai dan kesuksesan organisasi, karena dapat mengurangi waktu yang dibutuhkan untuk mempelajari kompetensi-kompetensi dan pandangan baru, serta dapat menghemat biaya secara signifikan. Knowledge di dalam organisasi bergantung pada kumpulan kontribusi dan individu, juga berevolusi karena ada review dari pihak lain, digunakan dan dipelajari dari sumber knowledge yang asli. Menurut (Debowski, 2006) yang dikutip oleh (Kurniali, 2012), ada lima tahapan dalam pengembangan knowledge pada suatu organisasi, yaitu: knowledge sourcing, knowledge abstraction, knowledge conversion, knowledge diffusion, knowledge development and refinement.

Knowledge sourcing merupakan proses dari penggambaran sebanyak mungkin informasi mengenai sumber knowledge. Sumber-sumber ini dapat meliputi spesialisasi ataupun knowledge yang sebelumnya dimiliki oleh individu di dalam organisasi, petunjuk dari para ahli seperti konsultan, catatan organisasi, atau intranet perusahaan. Setelah menganalisis sumber knowledge, prinsip dan konsep umum digeneralisasikan sebagai petunjuk dari konstruksi knowledge baru yang disebut sebagai knowledge abstraction. Knowledge Abstraction membantu dalam membuat kerangka pemahaman yang diperoleh dari knowledge sourcing dan untuk memperluas knowledge baru dari petunjuk-petunjuk dan masalah umum yang ada.

Knowledge conversion menggambarkan fase-fase selama berbagai ide dan prinsip disaring untuk hasil yang lebih spesifik. Knowledge dapat berupa baik codified ataupun embodied. Codified knowledge adalah knowledge yang dapat dicatat dan diakses oleh orang lain ketika dibutuhkan. Embodied Knowledge adalah tacit knowledge dari individu yang dapat dibagikan melalui cerita, metamorfosis, atau personal advice yang dibutuhkan. Embodied knowledge lebih sulit untuk diakses tanpa adanya keterikatan dengan pencipta knowledge.

Knowledge diffusion adalah penyebaran knowledge sekali knowledge tersebut di-codified atau embodied. Pada organisasi, difusi dapat terjadi melalui media komunikasi (contoh: newsletters, intranet, rapat, seminar, atau video), membuat model praktik-praktik baru, dan demonstrasi prosedur-prosedur khusus. 
Kesuksesan dari knowledge diffusion bergantung pada level knowledge sebelumnya yang dimiliki oleh peserta dan keefektifan dari saluran-saluran yang ada untuk berbagi knowledge. Difusi ini terjadi paling baik ketika penerima dapat mengerti dan mengintegrasikan pemahamanpemahaman yang ada pada konstruksi mentalnya sendiri.

\section{Knowledge}

development

and refinement merupakan proses evolusi pembentukan kembali dan menguji lebih jauh melalui penambahan pengalaman dan feedback, yang memastikan knowledge tetap berlaku sekarang dan bermanfaat. Organisasi perlu untuk memastikan bahwa penciptaan knowledge secara konstan di-review dan di-update untuk mencerminkan pemahaman-pemahaman baru yang sudah diperoleh.

\section{Lima Kunci Utama Integrasi Knowledge Management}

Menurut (Debowski, 2006) yang dikutip oleh (Kurniali, 2012) knowledge management bergantung pada keterkaitan dari lima kunci sistem untuk mencapai integrasi secara utuh dari organisasi, yang disebut sebagai five P's, meliputi: (1) planning - harus mengklarifikasikan tujuan dari knowledge dan membuat nilai-nilai dan proses yang efektif untuk mendukung tujuan tersebut. Tujuan jangka panjang dan jangka pendek harus didefinisikan secara jelas. Planning untuk infrastruktur teknologi sebaiknya juga merefleksikan tujuan Knowledge Management sehingga perencanaan dapat diimplementasikan dengan efektif; (2) people memiliki knowledge, mereka me-manage sistem dan proses. Komitmen people atas proses strategi knowledge sangat penting untuk kesuksesan secara keseluruhan. Mereka perlu untuk diberi keyakinan bahwa Knowledge Management merupakan suatu inisiatif strategi yang bernilai; (3) process - keterkaitan antara kebutuhan strategi, prinsip-prinsip, proses dan praktik harus di-manage secara hati-hati untuk memastikan bahwa prinsip-prinsip KM tidak patah ketika diimplementasikan; (4) products fokus pada core knowledge membantu untuk mengidentifikasi batasan produk knowledge yang sebaiknya diolah, didefinisikan, di-capture, dimanajemen, dan didistribusikan; performance - Knowledge Management perlu untuk di-review secara berkala untuk memastikan bahwa investasi finansial dan sosial secara positif mempengaruhi modal intelektual dan sosial organisasi.

\section{Aplikasi Knowledge Management System}

Ada beberapa tahap dalam mengembangkan aplikasi knowledge, yaitu dengan mengembangkan suatu knowledge framework, mengembangkan dan mengelola knowledge repositories, mengembangkan suatu service knowledge yang efektif, dan disertai dengan pengembangan pada knowledge setting. Dua hal yang perlu diperhatikan dalam pengembangan knowledge framework adalah bagaimana knowledge yang dimiliki perusahaan dapat disimpan, dibagikan, dan digunakan. Serta mengidentfikasi core knowledge perusahaan.

\section{Evaluasi Knowledge Management System}

Evaluasi penting untuk semua strategi knowledge management. Evaluasi dapat menyediakan informasi dari efek penerapan dan investasi knowledge (biaya, waktu, dan tenaga). (Debowski, 2006) yang dikutip oleh (Kurniali, 2012)(Tiwana, 2002) Evaluasi menyediakan kesempatan untuk menganalisis strategi yang sekarang dan memonitor tanggapan dari para pengguna dan efek terhadap bisnis proses dan hasil yang didapatkan. Setiap proses organisasi yang utama harus secara regular dievaluasi. Strategi evaluasi butuh diikutsertakan dalam proses perencanaan dan implementasi untuk memonitor keberhasilan dan untuk mengidentifikasikan masalah yang harus diselesaikan secepatnya. Hal yang perlu diperhatikan dalam evaluasi, yaitu: (1) menyediakan waktu dan feedback yang akurat dari efektivitas strategi knowledge yang berjalan; (2) mendapatkan informasi dari hasil strategi knowledge; (3) mengidentifikasikan masalah yang harus diselesaikan; (4) menyediakan perhitungan dari investasi organisasi dalam knowledge management.

\section{Komite Teknis (BadanStandardisasi Nasional, 2018)}

Komite Teknis Perumusan SNI sesuai Peraturan BSN Nomor 4 Tahun 2018 merupakan Komite yang dibentuk dan ditetapkan oleh BSN, beranggotakan perwakilan pemangku kepentingan untuk lingkup tertentu, dan bertugas melaksanakan perumusan SNI dan pemeliharaan SNI. Jumlah anggota Komite Teknis paling sedikit 9 (sembilan) orang dan paling banyak 15 (lima belas) orang. Keanggotaan Komite Teknis merepresentasikan pemangku kepentingan (stakeholder)yang meliputi unsur pemerintah, pelaku usaha dan/atau asosiasi terkait, pakar dan/atau akademisi di bidang yang relevan, dan konsumen dan/atau asosiasi terkait. 
Struktur organisasi Komite Teknis terdiri dari satu ketua, satu sekretaris, dan anggota. Dalam hal diperlukan, ketua dapat dibantu oleh satu wakil ketua. Struktur organisasi Komite Teknis dapat dilihat pada Gambar 1 berikut.

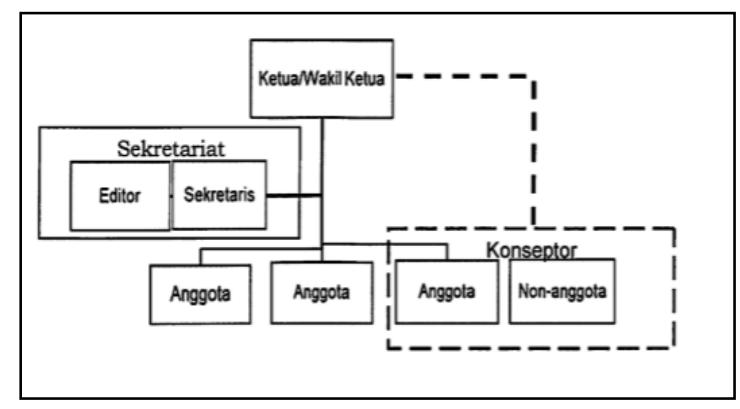

Gambar 1 Struktur organisasi Komite Teknis

Gambar 1 menyajikan struktur organisasi Komite Teknis. Keanggotaan Komite Teknis terdiri atas ketua merangkap anggota, wakil ketua merangkap anggota (bila diperlukan), sekretaris merangkap anggota, dan anggota. Sekretariat bertanggung jawab memberikan dukungan teknis dan administrasi untuk kelancaran tugas Komite Teknis meliputi: membantu ketua dan wakil ketua Komite Teknis dalam melaksanakan tanggung jawabnya, memfasilitasi dan menjamin kelancaran pelaksanaan kegiatan Komite Teknis, menyediakan referensi dan sumber daya yang diperlukan untuk kegiatan Komite Teknis, dan memelihara rekaman data dan informasi yang berkaitan dengan kegiatan Komite Teknis agar dapat diakses dan ditelusuri secara mudah. Konseptor bertugas menangani proses tertentu dalam kegiatan Komite Teknis. Konseptor dapat berasal dari anggota maupun non-anggota Komite Teknis. Editor SNI bertugas melaksanakan penyuntingan dan bertanggung jawab atas kebenaran penulisan rancangan SNI sesuai PSN yang relevan serta semua ketentuan teknis dan kesepakatan lain yang diperoleh melalui konsensus.

\section{Tugas dan Tanggung Jawab Komite Teknis (BadanStandardisasi Nasional, 2018)}

Tugas dan tanggung jawab Komite Teknis diatur dalam Peraturan Badan Standardisasi Nasional Nomor 4 Tahun 2018 tentang Pedoman Pengelolaan Komite Teknis. Tugas dan tanggung jawab Komite Teknis, yaitu: menyusun dan mengusulkan Program Nasional Perumusan Standar (PNPS), menetapkan konseptor dan editor RSNI, melaksanakan PNPS yang telah ditetapkan oleh Badan Standardisasi Nasional (BSN), melaksanakan pemeliharaan $\mathrm{SNI}$ sesuai ketentuan yang berlaku, menyusun dan merumuskan tanggapan Indonesia terhadap draft standar internasional dan dokumen lain yang terkait pengembangan standar internasional, melaksanakan tugas lain dalam rangka pengembangan standar nasional dan internasional sesuai kepentingan nasional, melaksanakan evaluasi program kerja dan partisipasi anggota Komite Teknis, dan menyusun laporan akhir tahun kinerja Komite Teknis.

\section{Perumusan dan Kaji Ulang Standar Nasional Indonesia (Badan Standardisasi Nasional, 2018) \\ Proses perumusan Standar Nasional} Indonesia (SNI) diatur dalam Peraturan Badan Standardisasi Nasional Nomor 3 Tahun 2018 tentang Pedoman Pengembangan Standar Nasional Indonesia. Proses perumusan terdiri dari perumusan konsep SNI oleh konseptor, yang menghasilkan Rancangan Standar Nasional Indonesia 1 (RSNI1). RSNI1 selanjutnya dibahas dalan Rapat Working Group/ Rapat Teknis dan apabila disetujui menjadi RSNI2. RSNI2 selanjutnya dibahas dalam Rapat Konsensus, dan jika disetujui maka dihasilkan RSNI3. RSNI3 selanjutnya diproses menjadi RASNI dan melalui proses jajak pendapat. Jika tidak terdapat komentar yang bersifat substansi, maka RASNI akan diproses penetapannya menjadi SNI. Namun jika terdapat tanggapan yang bersifat substansi, RASNI dibahas ulang dalam rapat Komite Teknis.

Rapat Teknis dilaksanakan minimal 1 (satu) kali selama periode Program Nasional Perumusan Standar (PNPS) dan dihadiri oleh anggota Komite Teknis serta konseptor nonanggota Komite Teknis, apabila dalam rapat diperlukan pertimbangan dari konseptor nonanggota Komite Teknis. Dokumen rapat teknis dan rapat konsensus harus disirkulasikan oleh Sekretariat paling lambat seminggu sebelum pelaksanaan rapat. Jika disetujui dalam rapat konsensus, RSNI3 yang telah diedit oleh editor kemudian diserahkan ke Badan Standardisasi Nasional paling lambat 10 (sepuluh) hari setelah pelaksanaan rapat teknis atau rapat konsensus. Editor SNI bertanggung jawab atas kebenaran penulisan rancangan Standar Nasional Indonesia bidang Teknologi Informasi sesuai PSN yang relevan serta semua ketentuan teknis dan kesepakatan lain yang diperoleh melalui konsensus.

Kaji ulang SNI merupakan salah satu kegiatan pemeliharaan standar yang diatur dalam Peraturan Badan Standardisasi Nasional Nomor 6 Tahun 2018 tentang Pedoman Kaji Ulang Standar Nasional Indonesia. Kaji ulang wajib dilaksanakan untuk SNI yang telah berumur atau ditetapkan lebih dari 5 (lima) 
tahun. Kaji ulang dilaksanakan oleh Komite Teknis yang difasilitasi oleh Sekretariat Komite Teknis. Kaji ulang menghasilkan rekomendasirekomendasi, yaitu: revisi, abolisi, tetap, amandemen, atau ralat. Tindak lanjut hasil/rekomendasi kaji ulang tetap adalah usulan penetapan kembali yang disampaikan melalui surat resmi dari Komite Teknis/Sekretariat kepada Badan Standardisasi Nasional. Tindak lanjut kaji ulang untuk rekomendasi revisi adalah diusulkan dalam Program Nasional Perumusan Standar (PNPS) tahun berikutnya atau tahun berjalan (jika melalui jalur keperluan mendesak) dan disampaikan melalui surat kepada BSN. Tindak lanjut kaji ulang untuk rekomendasi abolisi adalah usulan abolisi yang disampaikan melalui surat resmi dari Komite Teknis/Sekretariat kepada Badan Standardisasi Nasional.

\section{Model Waterfall}

Salah satu model yang banyak digunakan dalam pengembangan sistem yaitu model Waterfall (Pressman, 2005). Model Waterfall menggunakan pendekatan sistematik dan sekuensial yang dimulai pada tingkat dan kemajuan sistem pada seluruh tahapan. Tahapan dalam model Waterfall ialah analisis, desain, pengkodean, pengujian, dan pemeliharaan sistem (Pressman, 2005). Tahap analisis merupakan tahapan dimana kebutuhan sistem dianalisis, arsitektur sistem secara total ditentukan, serta penentuan ukuran dan jumlah data (Pressman, 2005). Tahap desain yaitu tahap ditentukannya dasar-dasar pembentukan dan pemilihan struktur data, struktur program, arsitektur program, pemilihan algoritma, dan interaksi dengan pengguna (Pressman,2005).

\section{Unified Modeling Language (UML)}

Unified Modeling Language (UML)adalah keluarga notasi grafis yang didukung oleh metamodel tunggal, yang membantu pendeskripsian dan desain sistem perangkat lunak, khususnya sistem yang dibangun menggunakan pemrograman yang berorientasi objek. Dalam model iteratif, diagram-diagram UML dapat digunakan dalam bentuk blueprint maupun sketsa. Dengan blueprint, diagram-diagram analisis biaya biasanya dibuat dalam iterasi sebelum membangun fungsi perangkat lunak. Setiap iterasi tidak dimulai dari coret-coretan kasar, tetapi dengan memodifikasi dokumen yang ada dengan menandai perubahanperubahan dalam iterasi yang baru. Rancanganrancangan blueprint biasanya diselesaikan terlebih dahulu dalam iterasi tersebut, dan dapat juga diselesaikan sedikit demi sedikit per bagian fungsi yang menjadi target iterasi. Perubahan pada rancangan blueprint dapat dikategorikan sebagai penyimpangan yang perlu ditinjau kembali oleh desainer yang membuat blueprint.

Penggunaan UML dalam model sketsa mengacu pada sebuah proses yang lebih dandapat berubah-ubah. Salah satu pendekatannya ialah menghabiskan beberapa hari di awal sebuah terasi untuk membuat sketsa rancangan iterasi tersebut. Selain itu, dapat juga dibuat sesi desain singkat di setiap titik selama iterasi, dan mengadakan sebuah rapat singkat selama kurang lebih setengah jam saat ditemukan fungsi yang tidak berjalan. Dengan blueprint, dapat diterapkan kode sesuai diagram. Sebuah rancangan sketsa biasanya diperlakukan sebagai potongan awal sebuah rancangan. Jika selama pengkodean ditemukan bahwa sketsa tersebut tidak sesuai, rancangan dapat diubah melalui diskusi untuk memahami seluruh percabangannya. UML 2 terdiri atas 13 (tiga belas) diagram yaitu activity, class, communication, component, composite structure, deployment, interaction overview, object, package, sequence, state machine, timing, dan use case diagram. Pada bagian ini hanya dibahas diagram-diagram yang digunakan pada tahap analisis dan perancangan sistem.

\section{Penelitian Sebelumnya}

Penelitian "Perancangan dan Pembangunan Knowledge Management System pada Modul Penelitian Menggunakan Framework Codeigniter dengan Metode Iterative Incremental" (Noferianti, L., Andrawina, L., \& Musnansyah, A., 2015) menggunakan kerangka kerja Codeigniter (Cl) dan metode iterative incremental dalam perancangan dan pembangunan Knowledge Management System (KMS) pada modul penelitian. Penelitian ini menghasilkan KMS yang dapat mendukung pengelolaan Beban Kerja Dosen (BKD) pada Fakultas Rekayasa Industri dan mampu memberikan evaluasi hasil kerja dari masingmasing dosen. Hasil penelitian tersebut menggambarkan bahwa dengan adanya KMS, dapat meningkatkan bussiness value dari Fakultas Rekayasa Industri dan menyajikan bahan evaluasi bagi masing-masing dosen dalam pelaksanaan Tri Dharma Perguruan Tinggi.

Penelitian "Perancangan dan Pembangunan Knowledge Management System pada Modul Pengabdian Masyarakat dan Penunjang Menggunakan Framework Codeigniter dengan Metode Iterative Incremental" (Ayundhana, N. P., Andrawina, L., \& Musnansyah, A., 2015) menggunakan kerangka kerja Codeigniter (CI) dan metode iterative incremental dalam perancangan dan 
pembangunan Knowledge Management System (KMS) pada modul pengabdian masyarakat. Penelitian ini menghasilkan KMS yang dapat mendukung dalam proses penambahan, pembaharuan data, dan penyimpanan arsip kinerja dosen sehingga mendukung proses transfer knowledge dari semester ke semester dengan tujuan agar kinerja dosen dapat menjadi lebih baik dari kinerja sebelumnya. Penelitian tersebut mengambil Fakultas Rekayasa Industri sebagai studi kasus.

Penelitian "Penerapan Tahapan Membangun Aplikasi Knowledge Management pada Subdivisi Orafin di PT X" menghasilkan suatu blueprint aplikasi Knowledge Management dengan studi kasus Subdivisi Orafin. Pada PT X khususnya Subdivisi Orafin pada saat penelitian tersebut dilakukan, belum dibangun Knowledge Management System (KMS). Dengan adanya KMS, dapat membantu Subdivisi Orafin dalam penyelesaian masalah (Kurniali , 2012).

Penelitian "Perancangan Knowledge Management System pada Bagian Diklat PT Dirgantara Indonesia" menggunakan The 10 Step Knowledge Management Road Map. Hasil dari penelitian ini adalah implementasi sharing knowledge dari Bagian Diklat PT Dirgantara Indonesia baik itu melalui forum online maupun forum offline (Aryani, 2014).

\section{Kerangka Penelitian}

Dalam penelitian ini, kerangka penelitian dapat dilihat pada Gambar 2 berikut.

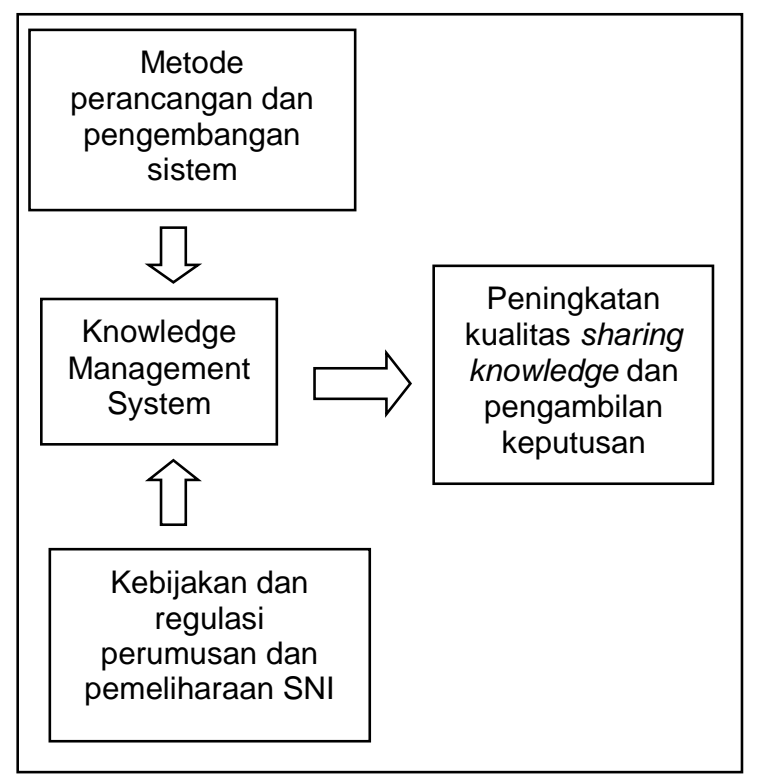

Gambar 2. Kerangka Penelitian

Pada Gambar 2 dapat dilihat bahwa dengan adanya pengelolaan pengetahuan yang baik dapat mendukung dan meningkatkan kualitas sharing knowledge dan pengambilan keputusan, yang pada akhirnya dapat meningkatkan kualitas kerja Komite Teknis. Untuk dapat mengelola pengetahuan dengan baik,diperlukan suatu sistem manajemen pengetatuan atau Knowledge Management System (KMS) yang dibangun sesuai dengan metode, kebijakan, dan regulasi yang berlaku.

\section{METODE PENELITIAN}

Dalam merancang Knowledge Management System (KMS) Komite Teknis digunakan langkah-langkah dari The 10 Step Knowledge Management Road Map yang diuraikan dalam Tiwana (2002) sebagaimana dikutip (Kurniali, 2012).

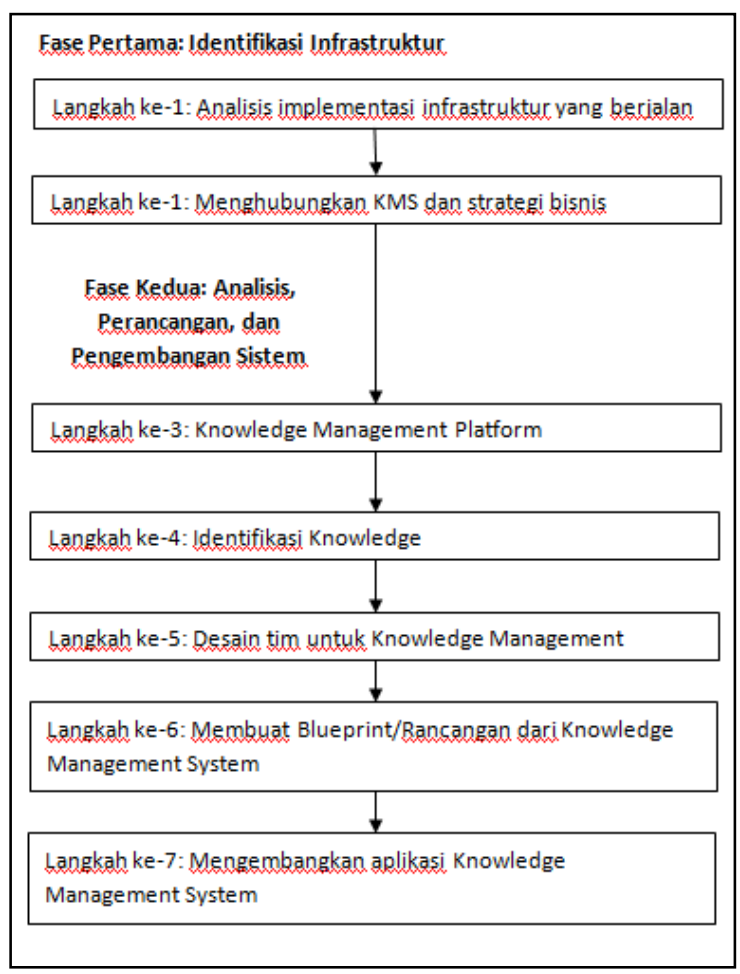

Gambar 3. Metodologi Penelitian

Gambar 3 menyajikan langkahlangkah/metodologi penelitian dengan detail langkah-langkah sebagai berikut:

\section{Fase Pertama: Identifikasi Infrastruktur}

Pada fase pertama ini meliputi dua tahap. Pada tahap pertama, diidentifikasi infrastruktur yang berjalan, yaitu dari sisi teknologi dan knowledge culture. Kemudian mengidentifikasi tahap-tahap konkrit yang dapat dilakukan untuk membangun platform KM. Pada tahap kedua, dilakukan identifikasi untuk menghubungkan KM dengan tujuan dan strategi bisnis. 


\section{Langkah ke 1: Analisis Implementasi Infrastruktur yang Berjalan}

Beberapa poin utama yang dianalisis dari infrastruktur berjalan, yaitu sebagai berikut: (1) mempelajari dan menganalisis topologi dari teknologi dan infrastruktur jaringan yang berjalan. Tujuannya adalah untuk mengetahui apakah teknologi dan infrastruktur jaringan saat ini sudah dapat mendukung penerapan $\mathrm{KM}$, yang memungkinkan informasi dapat diakses oleh semua bagian dengan mudah dan cepat; (2) mengintegrasikan, membangun, dan mengembangkan sumber daya yang sudah dimiliki oleh perusahaan, seperti media komunikasi, dan media-media penyimpanan data; (3) mendefinisikan framework teknologi yang diperlukan dalam pengembangan aplikasi KM. Dan mengidentifikasikan teknologi apa saja yang dapat digunakan dari infrastuktur yang berjalan; (4) mempelajari knowledge culture yang sudah berjalan. Tujuannya adalah supaya aplikasi yang akan dikembangkan dapat sesuai dengan kebiasaan yang sudah terbentuk selama ini, sehingga dapat diterima dan dapat diimplementasikan. Selain itu juga dapat memperbaiki kekurangan yang ada pada knowledge culture saat ini.

\section{Langkah ke 2: Menghubungkan Knowledge Management dan Strategi Bisnis}

Langkah ini menggunakan Zack Framework untuk mendefinisikan gaps yang ada di antara asset knowledge dengan strategi bisnis. Zack Furter mengatakan bahwa setiap strategi akan terhubung dengan sekumpulan sumber dan kapasitas knowledge (Tiwana, 2002) yang dikutip oleh (Kurniali, 2012). Zack Framework dapat mengidentifikasikan apa saja yang dapat dilakukan oleh organisasi, dengan menggunakan pengetahuan yang dimiliki saat ini. Dan dapat mengidentifikasikan apa yang harus dilakukan; dan pengetahuan apa yang diperlukan untuk mencapai tujuan dan visi dari organisasi. Dari dua informasi tersebut kita dapat melihat gap yang ada, sehingga dapat merancang suatu aplikasi untuk memenuhi kebutuhan knowledge tersebut.

Fase Kedua: Analisis, Perancangan, dan Pengembangan Sistem

Fase kedua dari implementasi KM meliputi analisis, perancangan, dan pengembangan dari sistem KM.

\section{Langkah ke 3: Knowledge Management Platform}

Pada langkah ini dilakukan analisis dan menentukan platform apa yang akan digunakan, berdasarkan beberapa kriteria utama yang harus dimiliki dari platform KM, yaitu (Tiwana, 2002) yang dikutip oleh (Kurniali, 2012): (1) efficient protocols - memungkinkan knowledge dibagikan dengan aman dan cepat; (2) portable operation dapat berjalan pada semua sistem operasi yang berbeda; (3) consistent and easy-to- use client interface - mudah untuk digunakan oleh user; (4) scalability - pada saat user bertambah banyak, platform harus dapat memenuhi permintaan seluruh user tanpa mengurangi performa; (5) legacy integration - harus dapat mengintegritaskan data ke final interface; (6) security - harus mempunyai pengamanan terhadap data; (7) flexibility and customizability mudah untuk diubah sesuai dengan kebutuhan user.

\section{Langkah ke 4: Identifikasi Knowledge di Komite Teknis}

Identifikasi dilakukan dengan observasi untuk mengetahui kebutuhan knowledge apa saja yang penting untuk disimpan pada aplikasi KM, sehingga dapat memenuhi kebutuhan pengguna akan knowledge. Serta untuk mengidentifikasi knowledge apa saja yang sudah ataupun belum terdokumentasi, agar kemudian dapat didokumentasikan dengan meng-input-nya ke dalam aplikasi Knowledge Management (KM) untuk mendukung proses knowledge sharing.

\section{Langkah ke 5: Desain Tim untuk Knowledge Management System}

Langkah pertama yang dilakukan dalam proses ini adalah membuat usulan struktur tim dari Komite Teknis beserta tugas dan tanggung jawab dari masing-masing anggota tim untuk implementasi aplikasi KM. Setelah struktur timnya selesai didefinisikan, langkah selanjutnya adalah membuat tim project untuk menangani pengembangan KM. Dalam membuat tim project ini, akan didefinisikan karakteristik dari setiap anggota tim yang dibutuhkan.

\section{Langkah ke 6: Membuat Blueprint/Rancangan} dari Knowledge Management System (KMS)

Knowledge Management System blueprint menyediakan rencana untuk membangun dan memperbaiki sistem KM. Dari hasil analisis infrastuktur dan rancangan teknologi yang telah dilakukan di awal, maka pada proses ini akan dibuat rancangan topologi jaringan dan infrastruktur yang baru. Selain itu, juga akan dibuat blueprint/rancangan dari aplikasi knowledge management yang akan dikembangkan. Blueprint/rancangan tersebut akan menggambarkan work flow, interaksi antar modul, dan fungsi-fungsi yang akan dibangun pada aplikasi KMS. 


\section{Langkah ke 7: Mengembangkan Aplikasi Knowledge Management System (KMS)}

Langkah terakhir yang akan dilakukan dari fase kedua adalah mengembangkan aplikasi KMS. Aplikasi ini akan dikembangkan dengan fitur-fitur antara lain sebagai berikut: (1) add and remove artikel - user dapat memasukan artikel baru sebagai sumber knowledge; (2) add Kategori dapat menambahkan kategori baru, sehingga pengelompokan artikel menjadi lebih terstruktur dan mudah untuk dicari; (3) users privilege pengaturan user dengan hak akses untuk melihat, memberikan feedback, melakukan perubahan, dan maintain knowledge; (4) feedback (comment) - user dapat memberikan feedback atas suatu knowledge melalui comment (dalam bentuk teks singkat yang ditambahkan pada artikel) dan rating (fitur vote apakah artikel membantu atau tidak); (5) approval - setiap artikel atau comment yang diinput harus di-approve dahulu baru bisa dipublish; (6) search - mempermudah pencarian artikel; (7) attachment - artikel dapat dilengkapi dengan dokumen-dokumen pendukung seperti gambar, video, dan PDF; (8) help desk menangani issue yang dikirimkan oleh user dan memberikan solusinya kepada user. Dalam pembangunan aplikasi, digunakan model Waterfall dan bahasa pemodelan Unified Modeling Language (UML).

\section{HASIL DAN PEMBAHASAN}

Berdasarkan kriteria Knowledge Management Platform, platform yang dipilih untuk mengembangkan aplikasi KM adalah web-based application. Berdasarkan hasil observasi, dapat disimpulkan bahwa knowledge yang penting untuk disimpan di aplikasi KM adalah sebagai berikut: (1) terjemahan kata dan istilah; (2) regulasi terkait organisasi dan keanggotaan Komite Teknis; (3) daftar laporan kegiatan Komite Teknis; (4) evaluasi kinerja Komite, (5) dokumen hasil kerja Komite, dan (6) daftar SNI dan statusnya. Struktur tim yang akan dibuat dalam implementasi aplikasi KM ini adalah: (1) admin - bertugas melakukan maintenance Aplikasi KMS (Add user, Setting Menu, Add/Remove Section \& Category) dan Trouble Shooting (konfigurasi server and aplikasi); (2) Sekretariat dan BSN - bertugas melakukan Add/Remove Articles, Help desk support, dan Research for new issue; (3) Sekretaris Komite Teknis - bertugas melakukan approval terhadap Articles/Comment baru yang akan dimasukan ke dalam aplikasi.

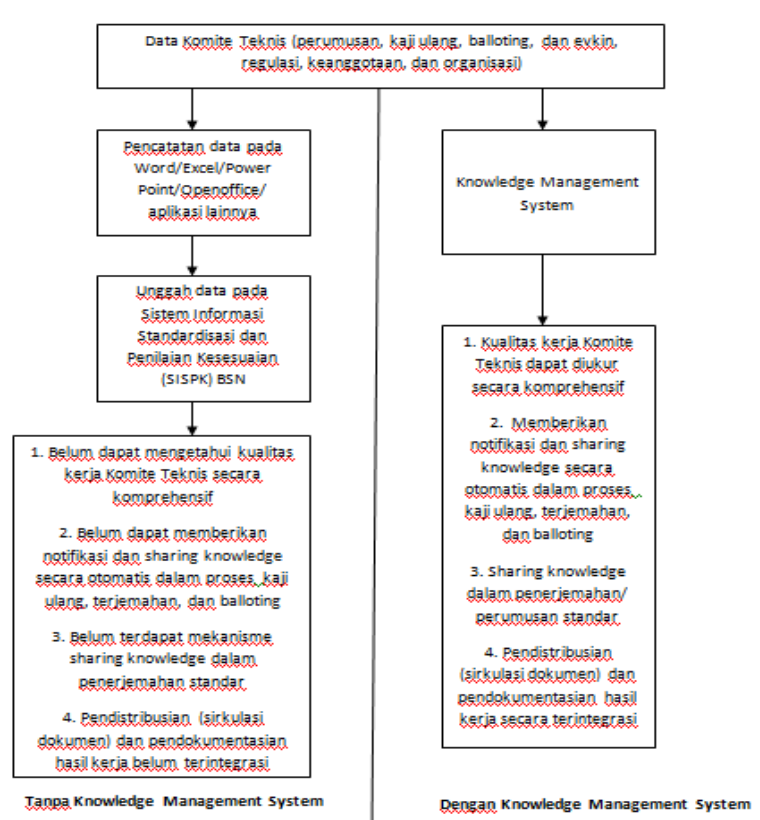

Gambar 3. Model Konseptual

Gambar 3 menyajikan model konseptual yang menggambarkan sistem yang ada saat ini (tanpa Knowledge Management System) dan sistem yang akan dibangun. Proses tanpa Knowledge Management System merupakan proses yang ada saat ini. Output yang ada dari proses saat ini menyajikan data mentah yang belum terintegrasi, yang perlu dikumpulkan dan diolah terlebih dahulu dalam proses pelaporan dan evaluasi kinerja Komite Teknis. Selanjutnya dengan penerapan Knowledge Management System seluruh data tersebut dapat terintegrasi, sehingga akan menghasilkan beberapa manfaat seperti kualitas kerja Komite Teknis dapat diukur secara komprehensif, sharing knowledge secara otomatis dapat dilakukan dalam proses kaji ulang, terjemahan dan balloting.

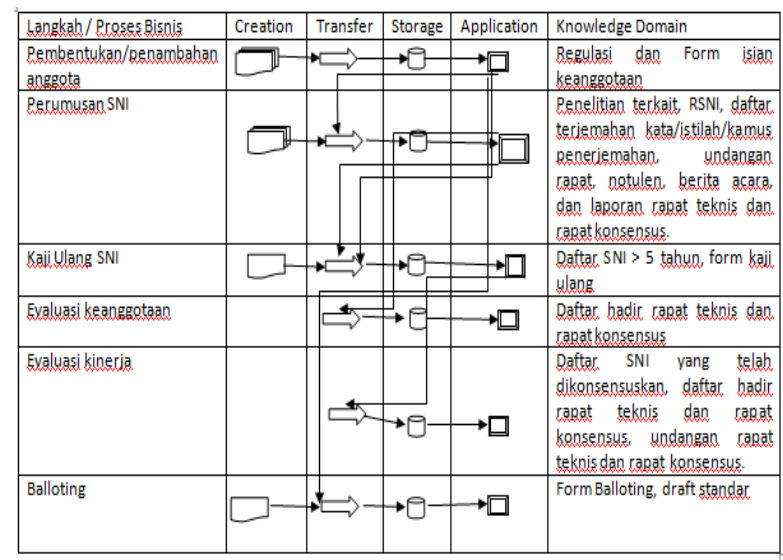

Gambar 4. Rancangan workflow Knowledge Management sesuai Proses Bisnis

Gambar 4 menyajikan model Knowledge Management sesuai proses bisnis/kerja Komite 
Teknis. Proses bisnis atau proses kerja mengacu pada tugas dan tanggung jawab Komite Teknis sebagaimana diatur dalam Peraturan Badan Standardisasi Nasional. Balloting merupakan proses pemberian tanggapan terhadap draft standar internasional. Proses perumusan, termasuk di dalamnya proses jajak pendapat.

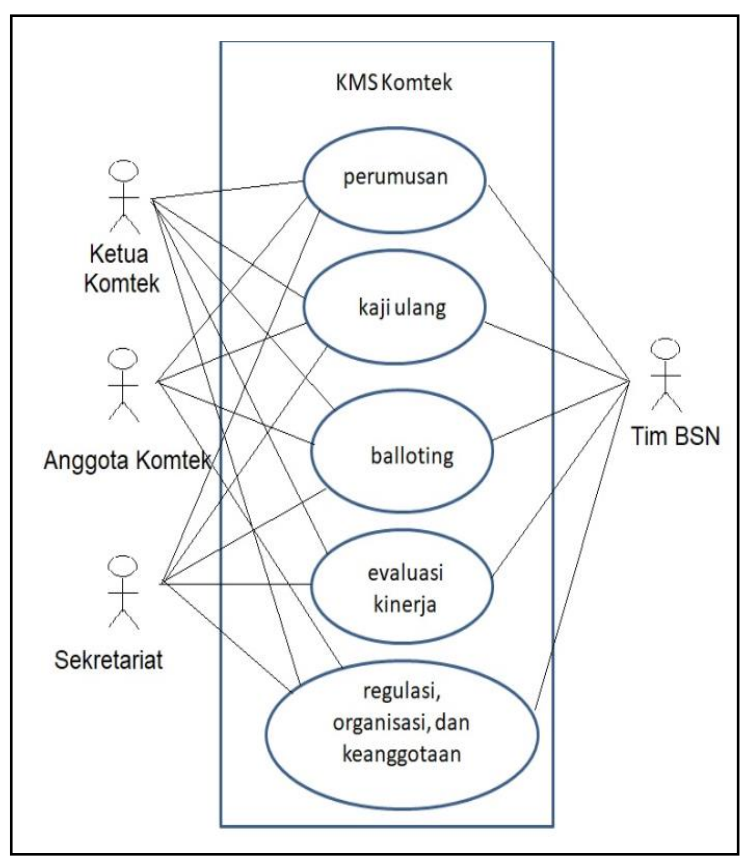

Gambar 5. Diagram Hasil Analisis dan Perancangan Kebutuhan Sistem

Gambar 5 menyajikan hasil analisis kebutuhan sistem dengan menggunakan usecase diagram. Fungsionalitas utama yang ada dalam aplikasi yaitu: perumusan, kaji ulang, balloting, evaluasi kinerja, dan regulasiorganisasi-keaggotaan. Fungsional tersebut sesuai dengan tugas dan tanggung jawab Komite Teknis sebagaimana diatur dalam Peraturan Badan Standardisasi Nasional.

Uji validasi secara umum bertujuan untuk menguji apakah perancangan Knowledge Management System (KMS) pada Komite Teknis sudah sesuai dengan proses-proses yang berjalan dan dapat digunakan di Komite Teknis. Uji validasi dilakukan dengan melakukan konfirmasi langsung melalui wawancara kepada Sekretariat Komite Teknis. Berdasarkan pada hasil wawancara diperoleh hasil bahwa proses yang ada pada perancangan KMS telah selaras dengan proses sebenarnya yang saat ini telah berjalan di Komite Teknis.

\section{KESIMPULAN}

Dari hasil penelitian diperoleh simpulan bahwa dengan adanya Knowledge Management System pada Komite Teknis dapat mendukung pelaksanaan tugas dan tanggung jawab Komite Teknis dan dengan menyediakan mekanisme sharing knowledge yang diperlukan. Saran dari penelitian ini yaitu agar Knowledge Management System dapat diintegrasikan dengan sistem lain, misalnya Sistem Informasi Standardisasi dan Penilaian Kesesuaian (SISPK) sehingga dapat mendukung koordinasi dan sharing knowledge antara BSN dengan Sekretariat dan anggota Komite Teknis.

\section{DAFTAR PUSTAKA}

Ayundhana, N. P., Andrawina, L., \& Musnansyah, A. (2015). Perancangan dan Pembangunan Knowledge Management System pada Modul Pengabdian Masyarakat dan Penunjang Menggunakan Framework Codeigniter dengan Metode Iterative Incremental. E-Proceeding of Engineering : Vol.2, No.2 Agustus 2015 page 5766.

Aryani, Ajeng Pritha. (2014). Perancangan Knowledge Management System pada Bagian Diklat PT Dirgantara Indonesia. Jurnal Manajemen Bisnis Indonesia: Vol 1 No 2 Februari 2014 page 197-213

Badan Standardisasi Nasional (2018). Peraturan Badan Standardisasi Nasional Republik Indonesia Nomor 3 Tahun 2018 tentang Pedoman Pengembangan Standar Nasional Indonesia.

Badan Standardisasi Nasional (2018). Peraturan Badan Standardisasi Nasional Republik Indonesia Nomor 4 Tahun 2018 tentang Pedoman Pengelolaan Komite Teknis Perumusan Standar Nasional Indonesia.

Badan Standardisasi Nasional (2018). Peraturan Badan Standardisasi Nasional Republik Indonesia Nomor 6 Tahun 2018 tentang Pedoman Kaji Ulang Standar Nasional Indonesia.

Becerra, Fernandez., et al, 2010., Knowledge Management, Systems and Process., Prentice Hall

Debowski, S. (2006). Knowledge Manageent. Milton, Qld.: Jhon Wiley \& Sons Australia.

Fowler, M. (2003).UML Distilled Third Edition: $A$ BriefGuide to the Standard Object ModelingLanguage, Covers through 
Version 2.0OMG UML Standard. Boston: AddisonWesley Publisher.

Kurniali, S. (2012). Penerapan Tahapan Membangun Aplikasi Knowledge Management Pada Subdivisi Orafin Di PT X.

Noferianti,L., Andrawina, L., \& Musnansyah, A. (2015). Perancangan dan Pembangunan Knowledge Management System pada Modul Penelitian Menggunakan Framework Codeigniter dengan Metode
Iterative Incremental. E-Proceeding of Engineering : Vol.2, No.2 Agustus 2015 page 5304.

Pressman, R.S. (2010). Software Engineering: APractitioner's Approach 7th edition. NewYork: McGraw-Hill.

Tiwana, A. (2002). The knowledge management toolkit : orchestrating IT, strategy, and knowledge platforms. Upper Saddle River, N.J: Prentice Hall. 